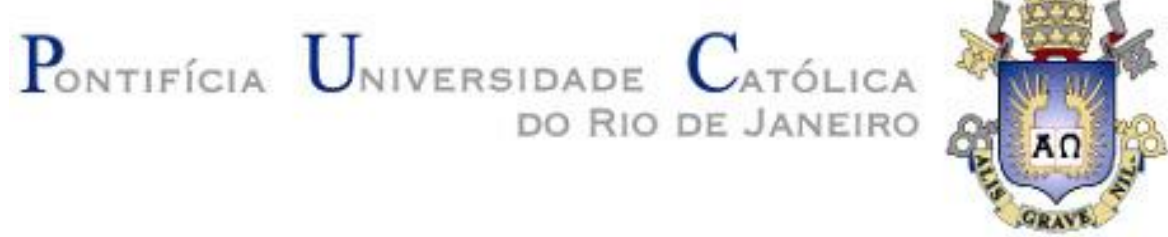

Ricardo Brandão Ferreira

\title{
Tratamento de Resíduos Sólidos: \\ Valoração por Opções Reais
}

\section{Dissertação de Mestrado}

Dissertação apresentada ao Programa de Pós-graduação em Administração de Empresas da PUC-Rio como requisito parcial para obtenção do título de Mestre em Administração de Empresas.

Orientador: Prof. Luiz Eduardo Teixeira Brandão

Rio de Janeiro

Novembro de 2010 


\section{Ricardo Brandão Ferreira}

\section{Tratamento de Resíduos Sólidos: Valoração por Opções Reais}

Dissertação apresentada como requisito parcial para obtenção do grau de Mestre pelo Programa de Pósgraduação em Administração de Empresas da PUCRio. Aprovada pela Comissão Examinadora abaixo assinada.

Prof. Luiz Eduardo Teixeira Brandão

Orientador

Departamento de Administração - PUC-Rio

Prof. Leonardo Lima Gomes

Departamento de Administração - PUC-Rio

Prof. Roberto Marcos da Silva Montezano

IBMEC

Profa. Mônica Herz

Vice-Decana de Pós-Graduação do CCS

Rio de Janeiro, 30 de novembro de 2010 
Todos os direitos reservados. É proibida a reprodução total ou parcial do trabalho sem autorização da universidade, do autor e do orientador.

\section{Ricardo Brandão Ferreira}

Graduou-se em Ciências Econômicas pela UERJ (Universidade do Estado do Rio de Janeiro) em 1995, concluiu a Pós-graduação em Finanças pelo IBMEC em 2001 e o Mestrado em Administração de Empresas pela PUC-Rio em 2010. Atuou na área de Investimentos de instituições financeiras multinacionais. Consultor na área de Planejamento Financeiro, seus interesses de pesquisa estão relacionados à avaliação econômica de projetos e planejamento estratégico.

Ficha Catalográfica

Ferreira, Ricardo Brandão

Tratamento de resíduos sólidos: valoração por opções reais / Ricardo Brandão Ferreira ; orientador: Luiz Eduardo Teixeira Brandão. - 2010.

88 f. ; $30 \mathrm{~cm}$

Dissertação (mestrado)-Pontifícia Universidade Católica do Rio de Janeiro, Departamento de Administração, 2010.

Inclui bibliografia

1. Administração - Teses. 2. Opções reais. 3. Resíduos sólidos. 4. Licitação. I. Brandão, Luiz Eduardo Teixeira. II. Pontifícia Universidade Católica do Rio de Janeiro. Departamento de Administração. III. Título. 
Aos meus pais e irmãs. 


\section{Agradecimentos}

A Deus pela força, principalmente, nas horas mais difíceis.

Ao meu orientador Prof. Luiz Eduardo T. Brandão pela habilidade em transmitir seu conhecimento em Opções Reais, despertando o meu interesse pelo o assunto e, orientação neste estudo.

Aos meus pais e irmãs que sempre me apoiaram na decisão de fazer o mestrado e, principalmente ao meu pai que, com grande experiência na área de resíduos sólidos, sempre esteve à disposição para enriquecer as discussões, além de contribuir com o levantamento dos dados, fundamental, para o desenvolvimento deste estudo.

Aos professores que participaram da Comissão examinadora.

A todos os professores e funcionários do Departamento pelos ensinamentos e ajuda.

Aos meus colegas da PUC-Rio.

A todos os familiares e amigos que de uma forma ou de outra me estimularam ou me ajudaram.

A todos que disponibilizaram informações e aos estudiosos e profissionais que me inspiraram a fazer o mestrado. 


\section{Resumo}

Ferreira, Ricardo Brandão; Brandão, Luiz Eduardo Teixeira. Tratamento de Resíduos Sólidos: Valoração por Opções Reais. Rio de Janeiro, 2010. 88p. Dissertação de Mestrado - Departamento de Administração, Pontifícia Universidade Católica do Rio de Janeiro.

Os serviços inerentes à Limpeza Pública no Brasil são de responsabilidade municipal. Para tanto, as prefeituras podem licitar a operação destes serviços à iniciativa privada. Essa dissertação propõe a utilização da metodologia das opções reais para valorar um projeto de tratamento de resíduos sólidos para o Município de Niterói, considerando que existem diversas flexibilidades gerenciais e significativas incertezas em relação ao volume de resíduos a serem tratados. Dado que pelas regras do edital número 02/2008, o vencedor seria a empresa que apresentasse o menor preço para os serviços, a estratégia adotada foi valorar o projeto considerando o valor presente líquido do projeto base (aterro sanitário) igual a zero com a possibilidade de adicionar a segregação e comercialização de recicláveis e a implantação de uma usina de geração de energia ao longo da vida útil da concessão. Tal estratégia resultou num valor presente líquido de $\mathrm{R} \$ 1.642 .000$.

\section{Palavras-chave}

Resíduos sólidos; opções reais; licitação 


\section{Abstract}

Ferreira, Ricardo Brandão; Brandão, Luiz Eduardo Teixeira (Advisor). Solid Waste Management: Valuation by Theory of Real Options. Rio de Janeiro, 2010. 88p. MSc. Dissertation - Departamento de Administração, Pontifícia Universidade Católica do Rio de Janeiro.

Public waste management services in Brazil are the responsibility of city municipalities, which may contract out the operation of these services to private enterprises. Within this work, the economic feasibility of a solid waste treatment project in the municipality of Niterói is analyzed in accordance with the rules established by the bid document $\mathrm{n}$ 02/2008. A real options approach was used for the analysis considering that there are many managerial flexibilities and significant uncertainties about the volume of waste to be treated. The bid rules award the contract to the lowest bidder, so the strategy used was to value the project considering the net present value of the base project (landfill) as equal to zero, and to consider the option of adding recycling facilities and the implementation of a power generation plant throughout the period of the concession. The result of this strategy was a net present value of $\mathrm{R} \$ 1.642 .000$.

\section{Keywords}

Solid waste; real options; bidding 


\section{Sumário}

1 Introdução 13

1.1 O problema 14

$\begin{array}{ll}1.2 \text { Objetivos } & 15\end{array}$

$\begin{array}{ll}1.3 \text { Estrutura da dissertação } & 16\end{array}$

2 Referencial teórico 17

2.1 Conceitos sobre investimentos produtivos 17

2.2 Histórico dos estudos de valoração de projetos 18

2.3 Fluxo de caixa descontado: importância e limitações 20

2.4 Opções financeiras $\quad 22$

2.5 Volatilidade 23

2.6 Modelo Black-Sholes-Merton 24

2.7 Movimento Geométrico Browniano 26

$\begin{array}{ll}2.8 \text { Opções reais } & 27\end{array}$

2.9 Análise da árvore de decisão 30

2.10 Modelo binomial 32

2.11 Limitações 34

3 Resíduos Sólidos 35

$\begin{array}{ll}3.1 \text { Definição } & 35\end{array}$

3.2 Classificação dos resíduos 35

3.3 Atividades gerenciais ligadas aos RSU 37

$\begin{array}{ll}3.3 .1 \text { Acondicionamento } & 37\end{array}$

$\begin{array}{ll}3.3 .2 \text { Coleta } & 38\end{array}$

3.3.3 Estação de transferência ou de transbordo 39

3.3.4 Estação de transferência ou de transbordo 39

3.4 A importância do setor de resíduos sólidos 42

3.5 O setor no Brasil e em Niterói 43

3.5.1 O cenário brasileiro 45

$\begin{array}{ll}3.5 .2 \text { Niterói } & 48\end{array}$ 
4 O projeto 50

4.1 O objeto de estudo 50

4.2 Projeto base $\quad 51$

4.2.1 Histórico 51

4.2.2 Localização e disponibilidade 52

4.2.3 Descrição do empreendimento 52

4.2.4 Tecnologias adotadas $\quad 54$

4.3 Fontes de receitas acessórias $\quad 54$

4.3.1 Energia elétrica por resíduos sólidos 54

4.3.2 Produtos recicláveis $\quad 55$

4.4 Metodologia de avaliação 56

4.5 Fluxos de caixa descontado (FCD) 57

4.5.1 Custo de Capital 57

4.5.2 FCD da adequação do Morro do Céu e da operação do ASN 57

4.5.3 FCD da geração de energia elétrica 62

$\begin{array}{ll}\text { 4.5.4 FCD dos reciclados } & 69\end{array}$

4.6 Aplicação da metodologia de opções reais 71

4.61 Determinação da volatilidade $\quad 72$

4.6.2 Outras premissas 73

4.6.3 Avaliação do projeto por opções reais 73

$\begin{array}{ll}\text { 4.6.4 Modelagem do ativo base } & 74\end{array}$

4.6.5 Modelagem do projeto com uma opção 76

4.6.6 Modelagem do projeto com duas opções 80

5 Conclusões $\quad 84$

6 Referências Bibliográficas $\quad 87$ 


\section{Lista de figuras}

Figura 1 - Árvore de Decisão 31

Figura 2 - Árvore Binomial 33

Figura 3 - Destino Final dos RSS Coletados pelos Municípios em 2009

Figura 4 - Modelo Binomial do Projeto Base 75

Figura 5 - Definição do Nó da Árvore $\quad 75$

Figura 6 - Árvore Binomial do Projeto Base $\quad 76$

Figura 7 - Modelagem com Uma Opção 78

Figura 8 - Árvore de Decisão com a Opção Energia 79

Figura 9 - Probabilidade dos Exercícios da Opção Energia 79

Figura 10 - Modelagem com Duas Opções $\quad 80$

Figura 11 - Árvore de Decisão com Opções Energia e Reciclados 81

Figura 12 - Probabilidades nos Exercícios das Opções Energia e Reciclados 82

Figura 13 - Análise de Sensibilidade (Vol.) 82

Figura 14 - Análise de Sensibilidade (Custo de Investimento EE) 83

Figura 15 - Análise de Sensibilidade (Custo de Investimento RC) 83 


\section{Lista de tabelas}

Tabela 1 - Diferenças entre Ativos Financeiros e Ativos Reais 29

Tabela 2 - Destinação Final dos RSU (milhões ton.) 46

Tabela 3 - FCD do Projeto Base (valores dividos por 1.000) 59

Tabela 4 - Geração e Venda de Energia: FCD até o 10 ano 64

Tabela 5 - Geração e Venda de Energia: FCD (valores divididos por 1.000) 65

Tabela 6 - Gás de Aterro Recuperável: 10 ano do MC 66

Tabela 7 - Investimentos (valores divididos por 1.000) 68

Tabela 8 - FCD dos Reciclados (valores divididos por 1.000) 69

Tabela 9 - Custos Operacionais $\quad 70$

Tabela 10 - Investimentos $\quad 71$

Tabela 11 - Taxas de Dividendos $\quad 74$ 


\section{Lista de abreviaturas}

ASN - Aterro Sanitário de Niterói

CLIN - Companhia de Limpeza de Niterói

FCD - Fluxo de Caixa Descontado

FEEMA - Fundação Estadual de Engenharia do Meio Ambiente

INEA - Instituto Estadual do Ambiente

$\mathrm{MC}$ - Aterro controlado do Morro do Céu

RSS - Resíduos de Serviços de Saúde

RSU - Resíduos Sólidos Urbanos 